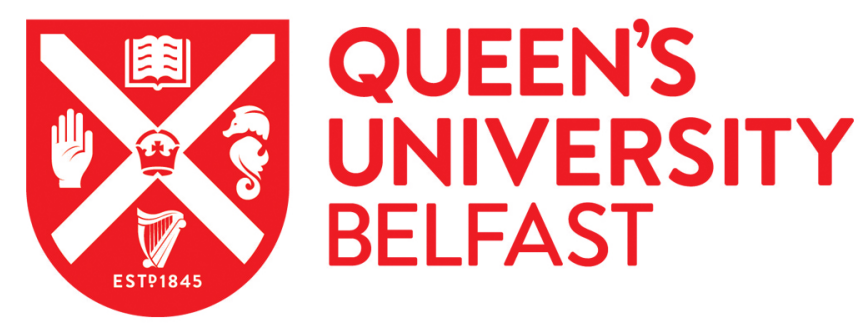

\title{
Investigating the Psychological Impact of Active Surveillance or Active Treatment in Newly Diagnosed Favorable-Risk Prostate Cancer Patients: A 9 month Longitudinal Study
}

Ruane-McAteer, E., Porter, S., O'Sullivan, J., Dempster, M., \& Prue, G. (2019). Investigating the Psychological Impact of Active Surveillance or Active Treatment in Newly Diagnosed Favorable-Risk Prostate Cancer Patients: A 9 month Longitudinal Study. Psycho-oncology, 28(8), 1743-1752. https://doi.org/10.1002/pon.5161

Published in:

Psycho-oncology

Document Version:

Peer reviewed version

Queen's University Belfast - Research Portal:

Link to publication record in Queen's University Belfast Research Portal

Publisher rights

@ 2019 John Wiley \& Sons, Ltd. This work is made available online in accordance with the publisher's policies. Please refer to any applicable terms of use of the publisher.

\section{General rights}

Copyright for the publications made accessible via the Queen's University Belfast Research Portal is retained by the author(s) and / or other copyright owners and it is a condition of accessing these publications that users recognise and abide by the legal requirements associated with these rights.

Take down policy

The Research Portal is Queen's institutional repository that provides access to Queen's research output. Every effort has been made to ensure that content in the Research Portal does not infringe any person's rights, or applicable UK laws. If you discover content in the

Research Portal that you believe breaches copyright or violates any law, please contact openaccess@qub.ac.uk. 
Manuscript title: Investigating the Psychological Impact of Active Surveillance or Active Treatment in Newly Diagnosed Favorable-Risk Prostate Cancer Patients: A 9 month Longitudinal Study

Running title: The psychological impact of active surveillance or active treatment Authors

1. *Eimear Ruane-McAteer, $\mathrm{PhD}^{\mathrm{a}}$ eruanemcateer01@qub.ac.uk

2. Sam Porter, $\mathrm{PhD}^{\mathrm{b}}$ porters@,bournemouth.ac.uk

3. Joe O'Sullivan, $\mathrm{MD}^{\mathrm{c}, \mathrm{d}}$ joe.osullivan@qub.ac.uk

4. Martin Dempster, $\mathrm{PhD}^{\mathrm{e}}$ m.dempster@qub.ac.uk

5. Gillian Prue, $\mathrm{PhD}^{\mathrm{a}^{*}}$ g.prue@qub.ac.uk

*Corresponding author

aschool of Nursing and Midwifery, Medical Biology Centre, Queen's University Belfast, 97 Lisburn Road, Belfast, N.Ireland

bepartment of Social Sciences and Social Work, Bournemouth University, Bournemouth, UK

${ }^{\mathrm{c}}$ The Northern Ireland Cancer Centre, Belfast City Hospital, N.Ireland

${ }^{\mathrm{d} C e n t r e}$ for Cancer Research and Cell Biology, Queen's University Belfast, N.Ireland eSchool of Psychology, Queen's University Belfast, N.Ireland 


\begin{abstract}
Objective

This study aimed to explore the psychological impact of favorable-risk prostate cancer (PCa) and associated treatment (Active Surveillance (AS) or Active Treatment (AT)), comparing prevalence and temporal variability of generalized anxiety, PCa-specific anxiety, and depression symptoms.

Methods
\end{abstract}

PCa patients were recruited at diagnosis prior to treatment decision-making and completed questionnaires assessing anxiety (STAI-6; MAX-PC) and depression symptoms (CES-D) at four timepoints for 9-months. Non-cancer controls were recruited via university staff lists and community groups. Results were analyzed using analysis of variance.

Results

Fifty-four PCa (AS n=11, AT n=43) and fifty-three non-cancer participants were recruited. The main effect of time or treatment group were not statistically significant for CES-D scores $(\mathrm{p}>0.05)$. The main effect of treatment on STAI-6 scores was significant $(F(2,73)=4.678$, $\mathrm{p}=0.012)$ with AS patients reporting highest STAI-6 scores ( $\mathrm{T} 1 \mathrm{M}=36.56$; $\mathrm{T} 2 \mathrm{M}=36.89$, T3 $\mathrm{M}=38.46$; $\mathrm{T} 4 \mathrm{M}=38.89$ ). There was a significant main effect for time since diagnosis on MAX-PC $(F(3,123)=3.68, \mathrm{p}=0.01)$, AS patient scored higher than AT at all timepoints $(\mathrm{T} 1$ $\mathrm{M}=10.33$ v 10.78; T2 M=11.11 v 11.30; T3 M=13.44 v 10.55; T4 M=11.33 v 8.88), however both groups declined overall with time.

Conclusions

Men undergoing AS had significantly higher anxiety symptoms than AT and non-cancer participants, contradicting previous literature. This may be due to perceived inactivity of AS relative to traditional narratives of cancer treatment. Participant experiences appear to be less favorable relative to other international centers. Recommendations for future research and clinical practice include the need to improve diagnosis and treatment information provision particularly for lower-risk patients.

Keywords

Active Surveillance; Cancer; Expectant Management; Longitudinal Research; Oncology; Prostatectomy; Prostatic Neoplasms; Psychological Adjustment; Radiotherapy; Surveys 


\section{Background}

Prostate cancer (PCa) is the most common male cancer worldwide, ${ }^{1}$ with data from the UK Office for National Statistics ${ }^{2}$ indicating a three-fold increase in the incidence of PCa in Britain over the last 30 years, although a decline in PCa mortality has also been observed. A $\sim 70 \%$ increase in the incidence of 'favorable-risk' PCa (i.e. Gleason score $\leq 7$, PSA $<20 \mathrm{ng} / \mathrm{mL}$ and clinical stage $\mathrm{T} 1-\mathrm{T}_{2} \mathrm{~b}^{3}$ ) has been observed ${ }^{4}$ attributed to the sensitivity of screening measures which can lead to overtreatment. ${ }^{5}$ The risk-benefit of treating low-tointermediate $\mathrm{PCa}$ can be challenging for patients to understand, ${ }^{6}$ especially when treatment can result in permanent and life-changing complications (e.g. impotence and incontinence ${ }^{7}$ ) without any proven disease modifying benefit.

There is a high potential over-treatment of lower risk PCa and subsequent possible sideeffects for men diagnosed with this type and stage of cancer. ${ }^{8}$ Evidence from a post-mortem study of men who died from a cause other than $\mathrm{PCa}$, found that $40 \%$ of men over 60 years, and $60 \%$ of men over 80 years had evidence of $\mathrm{PCa} .{ }^{9}$ The majority of the PCa cases diagnosed post-mortem were considered low-to-intermediate risk, supporting the phrase commonly used in the field that men with low-to-intermediate risk PCa are more likely to die 'with PCa than from PCa'.

Active surveillance (AS) was developed in response to the increasing numbers of men diagnosed with favorable-risk disease to avoid the potential side effects of curative treatments until the cancer progresses further. The current study is based on the UK's National Institute for Health and Care Excellence (NICE) guidelines which recommend that AS should consist of regular PSA tests, Digital Rectal Examinations (DRE), annual or biannual biopsies. ${ }^{3}$

Three systematic reviews have been conducted on the psychological impact of lower risk PCa and AS, ${ }^{10-12}$ each demonstrating that the majority of evidence concludes that AS patients demonstrate minimal psychological harm, supporting the assumption of many that lower risk disease equates to lower risk of psychological morbidity. However, despite the high quality of the reviews, the methodological limitations of the included studies, such as a lack of appropriate comparison/control groups, and unavailability of baseline data gathered prior to treatment decision-making, leading to the risk of selection bias ${ }^{12}$, suggest the need for further research. To our knowledge, this paper is the first to report on this baseline timepoint of a prospective, longitudinal study thereby allowing us to capture more accurately the psychological impact of a diagnosis of favorable-risk PCa. 
The aim of this study was to provide an indication of the psychological impact of favorablerisk PCa and its associated treatment plans, comparing the prevalence and temporal variability of generalized anxiety, PCa-specific anxiety (PCa patients only), and depression symptoms among men newly diagnosed with favorable-risk PCa, eligible for all treatment options including active surveillance (AS), and age-matched men not diagnosed with cancer.

\section{Methods}

\section{Procedures}

Two participant groups were included in this study: men diagnosed with favorable-risk PCa and a cohort of age-matched men with no cancer diagnosis. The group of men diagnosed with PCa was further subdivided into those who opted immediately for AT despite eligibility for AS, and those who chose to undergo AS. Process of follow up is illustrated in Figure 1.

PCa participants: Men eligible for AS but have not yet made their treatment decision, i.e. newly diagnosed with favorable-risk PCa, as defined by NICE (Gleason score $\leq 7$, PSA $<20$ $\mathrm{ng} / \mathrm{mL}$, clinical stage $\mathrm{T} 1-\mathrm{T} 2 \mathrm{~b}^{3}$. Participants were recruited in the regional Cancer Centre and outpatient Urology department of an academic hospital in Belfast, Northern Ireland between February and September 2016 during their diagnosis/treatment discussion appointment.

Comparison between peers with no cancer and men diagnosed with favorable-risk PCa was considered important to facilitate understanding of the overarching impact of screening, biopsy receipt, diagnosis of PCa, as well as variability in psychological and physical wellbeing associated with the ageing process more generally. ${ }^{13}$ Non-cancer control participants were recruited using a combination of peer-nomination ${ }^{14-16}$ and advertising to local men's and retirement groups and university staff list. Eligible men were $>55$ years old, were not diagnosed with any form of cancer, or other condition that may have affected their emotional wellbeing (as self-reported by participants).

Both participant groups completed questionnaires at their leisure and returned questionnaires using pre-paid return envelope. The researcher was not present for questionnaire completion, however contact direct telephone and email was provided should participants have queries regarding any aspect of the study including the questionnaire.

Full details of sample and recruitment are available elsewhere. ${ }^{13}$ Ethical approval was granted by ORECNI (15/NI/0210) and NHS R\&D office (15093SP-SS). All participants provided written informed consent prior to participation. 
The sample size was calculated using GPower software (2007), effect size and sample size was calculated based on mean score and standard deviation on the State-Trait Anxiety Inventory short form (STAI-6) ${ }^{17}$ in two populations; data from a population of men diagnosed with low-to-intermediate risk $\mathrm{PCa}$, prior to treatment ${ }^{18}$ and men of a similar age group from the general population. ${ }^{19}$ At 0.8 power, $\mathrm{p}$ value 0.05 , and an effect size of 0.503 , the required sample size was 50 participants per group, 10\% was added to this, resulting in a final sample size of $55 \mathrm{PCa}$ patients, and 55 non-cancer controls.

This was considered exploratory work therefore $\mathrm{p}$ values were not adjusted for multiplicity. ${ }^{20}$ Rather, exact $\mathrm{p}$ values are reported where possible, to allow the reader to make their own judgements about statistical significance.

\section{Measures used}

Men with PCa were invited to complete outcomes at four timepoints (pre-treatment decisionmaking, 3, 6 and 9 months post decision). Non-cancer participants completed questionnaires at equivalent times (Figure 1).

Symptoms of generalized anxiety (STAI-6 ${ }^{17}$ ), PCa-specific anxiety (Memorial Anxiety Scale for Prostate Cancer; MAX-PC ${ }^{21}$ ), and depression (Centre for Epidemiologic Studies Depression Scale; CES-D ${ }^{22}$ ) were the primary outcomes of the study. All scales used have been utilized previously in cancer populations ${ }^{13,23,24}$. Clinical and socio-demographic were collected (e.g. age, disease profile, ethnicity, education, employment, relationship, sexual orientation).

STAI-6 scores can range from 20 to 80 , and a score $\geq 44$ was considered clinically significant ${ }^{17}$. Internal consistency was high (Cronbach's $\alpha=0.79$ ), as was concurrent validity with longer forms of the scale $(r>0.9),{ }^{17}$ MAX-PC possible scores range from 0 to 54 and patients with scores of $\geq 27$ were considered clinically significant ${ }^{21}$. MAX-PC total scores showed high internal consistency (Cronbach's $\alpha=0.89)$, test-retest reliability $(r=0.26-0.68)$, and construct validity when correlated with HADS total scores $(r=0.52)$ and HADS Anxiety Subscale $(r=0.57) .{ }^{21}$ For the CES-D, scores could range from $0-60$, scores were considered clinically significant when participants scored $\geq 16$. For all three scales higher scores indicated higher psychological distress. CES-D has shown high internal consistency (Cronbach's $\alpha=0.85-0.9)$, test-retest reliability ( $r=0.45-0.70)$, and construct validity with SF36 Mental Health Summary Scale $(r=0.65){ }^{22}$ 
Self-rated quality of life (QoL) was measured using the visual analogue scale (VAS) tool from EQ-5D ${ }^{25}$. Participants were asked to self-rate current health status on a visual scale of 0100 , with 100 representing the 'best health you can imagine'.

PCa knowledge was assessed using a scale developed by van den Bergh, et al. ${ }^{23}$ Possible score range was 0 to 15 , a score of 15 indicated maximum PCa knowledge. Although the PCa knowledge scale was initially developed in Dutch, the scale was translated into English using forward-backward translation.

Involvement of the clinician in decision-making was also assessed using an item developed by van den Bergh, et al. ${ }^{26}$ ("Who had the major part [i.e. who had the most influence] in the choice for your chosen treatment: you or your clinician?"), with 5 possible response options, resulting in a score range of 1-5, with 1 representing that the treatment decision was that of the patient and 5 representing that the treatment decision was that of the clinician.

\section{Statistical analysis}

Participant demographic characteristics were summarized descriptively. Generalized anxiety and depression scores were analyzed using a (4)x3 MANOVA with the within-subjects factor of time since diagnosis (baseline, T1; 3months, T2; 6months, T3, 9months, T4) and the between-subjects factor of participant type (AS, AT, non-cancer). PCa-specific anxiety scores were analyzed using a (4)x2 mixed-ANOVA with the within-subjects factor of time since diagnosis (baseline, T1; 3months, T2; 6months, T3, 9months, T4) and the betweensubjects factor of participant type (AS, AT). Post-hoc tests have only been included where the MANOVA or ANOVA demonstrated a statistically significant result. Based on mixed ANOVA protocol, participants were excluded from the analysis if data was missing at any one time-point. The ANOVA for PCa-specific anxiety was not included in the MANOVA as it only examined the difference between two groups, whereas for generalized anxiety and depression three groups were included.

\section{Results}

Of the 91 eligible PCa patients approached during their outpatient clinic appointment, 54 returned completed questionnaires (response rate, 59\%). Advertising through community groups and university staff distribution lists were the most effective non-cancer recruitment method as only one non-cancer participant was recruited using peer-nomination. Sixty-five men expressed an interest in participating in the study following advertising, of whom 52 
returned questionnaires (response rate, 80\%). This resulted in a total of 53 non-cancer participants. Retention rates remained high $(>80 \%)$ throughout Time 2 to Time 4 (3-9 months) in both participant groups (Figure 2). Reasons for PCa non-participation at Time 1 are listed in Table S1 (Supplementary Material).

Participant demographic characteristics are reported in Table 1. The PCa sample was predominantly white, married/in a significant relationship, and heterosexual. Mean age was AS: 64.9 years (SD, 5.79); AT: 62.2 years (SD, 6.58); and non-cancer: 61.8 years (SD, 5.90). Most PCa participants $(77.8 \%, 43 / 54)$ opted for AT despite being eligible for $\mathrm{AS}^{3}$. Of those 43 men who underwent AT, 15 opted for external beam radiotherapy (34.88\%), 11 for brachytherapy (25.58\%), 15 for radical prostatectomy (34.88\%), 2 did not specify type of AT $(4.65 \%)$. The clinician appeared to have a greater role in the treatment decision-making of AS patients compared to AT patients, with $55.5 \%(n=5)$ AS patients reporting that their clinician made the biggest contribution to treatment decision-making, compared to $27.8 \%$ $(\mathrm{n}=10)$ AT patients. Conversely, most AT patients felt they made the biggest contribution $(38.9 \%, n=14)$ compared to $11.1 \%(n=1)$ of AS patients. A third of both AS $(n=3)$ and AT patients $(n=12)$ reported that decision-making was equal between patient and clinician.

Summary scores for CES-D, STAI-6, and MAX-PC are reported in Table 2. Patients who continued on to AS and AT patients had relatively similar STAI-6 and CES-D scores at baseline, however MAX-PC scores were significantly higher in AS patients. The MAX-PC scale focuses on PCa symptom burden and progression, factors that AS patients likely had to consider when making their treatment decision. From T2 on, AS patients reported consistently higher scores in generalized anxiety, PCa-specific anxiety, and depression relative to AT patients. Non-cancer controls had the lowest reported psychological scores that stayed low and stable throughout follow-up.

No AS participants switched to AT over the course of the 9 month follow-up.

Based on chi-square analysis, the PCa and non-cancer samples were well matched in terms of ethnicity $(\mathrm{t}(53)=0.991, \mathrm{p}=0.324)$, sexual orientation $(\mathrm{t}(51)=1.352, \mathrm{p}=0.182)$, relationship $(\mathrm{t}(101)=0.331, \mathrm{p}=0.741)$, employment status $(\mathrm{t}(103)=0.643, \mathrm{p}=0.522)$, and age $(\mathrm{t}(103)=0.757$, $\mathrm{p}=0.451)$. However, significantly higher numbers of the non-cancer population reported third-level education $(\mathrm{t}(95.17)=6.248, \mathrm{p}<0.001)$, likely a result of the sampling/recruitment strategy adopted. 
Analysis of variance (independent samples t-test) indicated that there was no statistically significant difference in the anxiety reported by PCa responders and PCa non-responders on the 1 -item anxiety scale $(\mathrm{t}(5.45)=-1.019, \mathrm{p}=0.351)$.

ANOVA showed that there was no statistically significant difference in baseline self-reported QoL between the three participant groups (AS, AT, non-cancer (EQ-5D-5L VAS; $F(2,102)=1.45, \mathrm{p}=0.239))$. There was also no statistically significant differences between baseline PCa knowledge in men who later opted for AS (M, 11.27, SD, 1.90) compared to AT patients $(\mathrm{M}, 10.79, \mathrm{SD}, 2.96 ; \mathrm{t}(52)=0.512, \mathrm{p}=0.611)$. Therefore, neither physical symptom experience nor knowledge differential is likely to have influenced the reported differences in psychological wellbeing between groups.

\section{Generalized Anxiety and Depression}

A mixed (4x3) MANOVA for the combined outcomes of STAI-6 and CES-D swas conducted. The main effect of time $(\mathrm{F}(6,68)=0.893, \mathrm{p}=0.505)$ and the interaction between time and group $(\mathrm{F}(6,69)=1.588, \mathrm{p}=0.164)$ were not statistically significant. However, the main effect of group was statistically significant $(\mathrm{F}(2,73)=4.678, \mathrm{p}=.012)$. To further explore the significant main effect of group the outcome measures were examined separately and it was found that the multivariate significant effect arose from significant differences between groups in terms of STAI-6 scores $(\mathrm{F}(2,73)=4.450, \mathrm{p}=.015)$ but not CES-D scores $(\mathrm{F}(2,73)=2.241, \mathrm{p}=.114)$.

Post hoc Tukey tests for the main effect of group on STAI-6 found that the non-cancer group scored significantly lower than the AS group $(p=0.039)$ but not the AT group $(p=0.064)$. There was no significant difference between the AS and AT groups $(\mathrm{p}=0.614)$.

\section{PCa-specific Anxiety}

In the mixed ANOVA for MAX-PC, Mauchly's test was not significant therefore sphericity assumed values were interpreted. There was a statistically significant main effect for time since diagnosis on MAX-PC scores; $F(3,123)=3.68, \mathrm{p}=0.014$. The main effect of treatment type (AS, AT) was not statistically significant; $F(1,41)=3.92$, $\mathrm{p}=0.054$. The interaction between time since diagnosis and treatment type was also not statistically significant; $F(3,123)=0.135, p=0.939$. AS patient scores were higher than AT at all timepoints, however both groups' scores generally declined steadily between T1-T3, with scores remaining stable between $\mathrm{T} 3$ and $\mathrm{T} 4$. 


\section{Conclusions}

Results of the present study suggest that treatment type (i.e. AS or AT) has a significant impact on psychological wellbeing up to 9 months post-diagnosis of favorable-risk PCa. The extent of this impact varies over time, however AS patients consistently reported higher scores on measures assessing anxiety and depression symptoms.

This paper is, to our knowledge, the first to report on the crucial post-diagnosis but pretreatment decision-making time-point. This longitudinal study examined the psychological wellbeing of men eligible for AS. The paucity of such data to date has significantly limited the conclusions that could be drawn from previous research. ${ }^{12}$

Although from one geographical region, the sample is in some respects reflective of PCa globally ( $70 \%$ of cancers occurring in the developed world ${ }^{27}$ ) and provides a useful indication of the psychological well-being of men with lower-risk PCa prior to AS. Men who later opted for AS had the highest PCa-specific anxiety symptoms (MAX-PC) at baseline (Time 1), the only difference between groups at baseline, likely a result of the focus of the MAX-PC on PCa symptom burden, monitoring approaches, and disease progression which are factors considered when considering AS. Data from the Time 1 indicates that despite no significant differences in general psychological wellbeing (generalized anxiety and depression symptoms), physical QoL, or PCa knowledge, the majority of men opt for AT risking debilitating treatment induced urinary, sexual, and bowel dysfunction, in spite of eligibility for AS.

Over $77 \%$ of men eligible for all treatment options including AS did not opt for AS. Although it was anticipated that a proportion of the men included in the study would opt for immediate curative treatment due to personal preferences, the extent of this was unexpected. The lack of differences in perceived QoL and PCa knowledge between participant groups suggests that these patterns of patient treatment decision-making was not a result of physical side-effects or knowledge of cancer. Qualitative data into the treatment decision making of patients who opted for AS of the present study is currently in preparation for publication. ${ }^{28}$

On all three psychological outcome measures used, overall AS patients had the least favorable scores across timepoints. Although PCa-specific anxiety symptoms tended to decline over time for both AS and AT patients, AS patients remained significantly higher than AT at all timepoints. Generalized anxiety symptoms increased with time since diagnosis for AS patients, and depression symptoms increased up to 6 months post-baseline before 
dropping slightly at 9 months. AT patient psychological dysfunction generally decreased with time. Non-cancer control participants' psychological dysfunction remained stable and low across timepoints.

Non-cancer participants demonstrated the highest psychological wellbeing on all quantitative psychological measures in comparison to the PCa patient groups. The high scores on anxiety and depression symptoms observed in men with favorable-risk PCa suggests that medical perception that a favorable-risk diagnosis (as compared to a later stage, higher risk diagnosis requiring immediate curative treatment) carries with it favorable psychological morbidity, may not necessarily be the case. The assumption that patients are not experiencing distress is inaccurate, and may be a factor in uptake of potentially unnecessary $\mathrm{AT},{ }^{29}$ as despite eligibility for AS, the majority of participants opted for AT (e.g. RP, RT, or BT).

The increase in AS patients' generalized anxiety symptoms over time contradicts previous research that reported declining anxiety in this group. ${ }^{23,24,30-34}$ Much of international AS research has been conducted on men being managed in centers with a strong focus on AS who have been refining and perfecting the diagnosis experience for almost two decades and therefore AS is more widely accepted by clinicians and patients. ${ }^{19,26}$ This study demonstrates that men's experience of diagnosis in a non-specialist AS center appears to be different. Centers with the specialist focus on AS should be used as a guide to improving men's experiences in non-specialist AS institutions. The literature reporting favorable outcomes of AS patients managed in specialist institutions must be interpreted with caution when applying findings to non-specialist institutions.

We should not underestimate the importance of the clinician in the decision to undergo AS. The Salzburg Statement on Shared Decision-Making ${ }^{35}$ states that the medical community has an ethical imperative to ensure patients are fully aware of the nature of their illness, and the communication of illness characteristics must be targeted to individual patient needs. Results from a previous trial demonstrate that it is "quite possible, using trained counsellors, to convey the appropriate information about not needing to rush a decision" ${ }^{36,37}$ Other research, however, has discussed the impact of giving patients choice without sufficient support to make that choice, and reported that this leaves patients feeling "abandoned rather than autonomous". ${ }^{38}$ A previous study examining decision making in PCa patients has shown that even when using decision aids, information provided was not well understood ${ }^{39}$. This has 
important implications for PCa patients diagnosed with favorable-risk disease who have AS and a range of AT options open to them, with little difference in survival rates.

\section{Study limitations}

Questionnaires used to assess psychological wellbeing were based on self-report leading to potential bias. Further, the scales used (CES-D, STAI-6, MAX-PC) are not validated for diagnosis of depressive or anxiety disorders, rather they provide an indication of a number of the symptoms associated with such diagnoses therefore findings should be interpreted with this in mind.

The majority of the sample was white, in a significant relationship/married, and heterosexual. This demographic profile is generally consistent with this age group and geographic location from which this study sample is drawn, ${ }^{40}$ however lack of men from African and AfroCaribbean ethnicity means that the results are not generalizable beyond this population. Education level also differed between PCa and non-cancer participants, likely a result of one of the recruitment methods for non-cancer participants. Due to slow recruitment from peernomination, as well as the community and men's groups, recruiting from university staff lists was considered a necessary recruitment strategy. We ensured all staff across the university received the invitation (i.e. security, maintenance, estates, teaching, research etc) in an attempt to improve educational heterogeneity of the sample.

Despite lack of statistical power, results of this study are important to consider when designing future research in this area.

\section{Clinical implications}

Findings suggest that the clinician plays an important role in patient treatment decisionmaking, and that men had varying levels of psychological wellbeing post-diagnosis based on that treatment decision-making. Health Care Professionals must ensure their patients have an accurate understanding of the favorable-risk nature of their disease and should not assume that there is a linear, positive relationship between PCa severity and distress. This study suggests that when patients are faced with a diagnosis of lower-risk PCa and all the treatment options that come with that diagnosis, they report adverse psychological wellbeing. Previous research demonstrates that the most favorable psychological outcomes occur when patients have a role in treatment decision-making. ${ }^{38}$ Clinicians must support patients to make the most appropriate treatment decisions based on patient priorities and clinical judgement, to achieve 
the most favorable outcomes for their patients in terms of survival, physical QoL, and psychological wellbeing.

Future research should explore how patient individual differences (e.g. personality, baseline psychological wellbeing, health literacy) can be incorporated into clinical practice when attempting to communicate diagnosis and treatment information to promote accurate patient understanding of prognosis, and potential adverse side-effects of treatments to enhance patient care and experiences of diagnosis and treatment. In the longer term, this should help reduce financial burden associated with over-treatment and maximize patient wellbeing.

\section{Data availability statement}

The data that support the findings of this study are available on request from the corresponding author. The data are not publicly available due to privacy/ethical restrictions.

\section{Acknowledgements}

The authors wish to acknowledge staff at Belfast City Hospital, Northern Ireland Cancer Centre, and administrative staff at Queen's University Belfast for their logistical support throughout the duration of the study, and participants for their time.

\section{Conflict of interests}

The authors declare no conflicts of interest.

\section{Funding}

The study was funded as part of the first author's PhD, supported by the School of Nursing and Midwifery and the School of Medicine, Dentistry and Biomedical Science at QUB.

\section{Authors' Contributions}

ER, SP, JO'S, and GP contributed to the conceptualization, methodology, and investigation of the article. ER was responsible for data analysis under the supervision of MD. ER drafted the article. MD, SP, JO'S, and GP provided critical revisions. All the authors read and approved the final manuscript. 


\section{References}

1. Ferlay J, Steliarova-foucher E, Lortet-tieulent J, Rosso S. Cancer incidence and mortality patterns in Europe : Estimates for 40 countries in 2012. Eur J Cancer [Internet]. 2013;49(6):1374-403. Available from: http://dx.doi.org/10.1016/j.ejca.2012.12.027

2. King A, Broggio J. Cancer registration statistics, England 2016. 2018;1-22.

3. National Institute for Health and Care Excellence (NICE). Putting NICE guidance into practice Prostate cancer : protocol for active surveillance Implementing the NICE guideline on. 2014;(January).

4. Carter HB, Albertsen PC, Barry MJ, Etzioni R, Stephen J, Greene KL, et al. Early Detection of Prostate Cancer: AUA Guideline. 2013;190(2):419-26.

5. Lawrentschuk N, Klotz L. Active surveillance for low-risk prostate cancer: an update. Nat Rev Urol. 2011;8(6):312-20.

6. Frame I, Cant S. Current challenges in prostate cancer: An interview with Prostate Cancer UK. BMC Med [Internet]. 2015;13(1):1-6. Available from: http://dx.doi.org/10.1186/s12916-015-0411-7

7. Cooperberg MR, Carroll PR, Klotz L. Active surveillance for prostate cancer: Progress and promise. Vol. 29, Journal of Clinical Oncology. 2011. p. 3669-76.

8. Bangma CH, Roemeling S, Schröder FH. Overdiagnosis and overtreatment of early detected prostate cancer. World J Urol. 2007;25(1):3-9.

9. Zlotta AR, Egawa S, Pushkar D, Govorov A, Kimura T, Kido M, et al. Prevalence of prostate cancer on autopsy: cross-sectional study on unscreened Caucasian and Asian men. J Natl Cancer Inst [Internet]. 2013 Jul 17 [cited 2015 Jan 5];105(14):1050-8. Available from: http://www.ncbi.nlm.nih.gov/pubmed/23847245

10. Bellardita L, Valdagni R, Van Den Bergh R, Randsdorp H, Repetto C, Venderbos LDF, et al. How does active surveillance for prostate cancer affect quality of life? A systematic review. Eur Urol [Internet]. 2015;67(4):637-45. Available from: http://www.europeanurology.com/

11. Carter G, Clover K, Britton B, Mitchell J. A, White M, McLeod N, et al. Wellbeing 
during Active Surveillance for localised prostate cancer: a systematic review of psychological morbidity and quality of life. Cancer Treat Rev [Internet].

2015;41(1):46-60. Available from:

http://search.ebscohost.com/login.aspx?direct=true $\& d b=j$ lh $\& A N=2012900185 \&$ site $=e$ host-live

12. Ruane-McAteer E, Porter S, O’Sullivan JM, Santin O, Prue G. Active surveillance for favorable-risk prostate cancer: Is there a greater psychological impact than previously thought? A systematic, mixed studies literature review. Psychooncology. 2017;26(10).

13. Ruane-McAteer E, O'Sullivan J, Porter S, Venderbos L, Prue G. An exploration of men's experiences of undergoing active surveillance for favourable-risk prostate cancer: A mixed methods study protocol. BMC Cancer. 2016;16(1).

14. Jacobsen PB, Hann DM, Azzarello LM, Horton J, Balducci L, Lyman GH. Fatigue in Women Receiving Adjuvant Chemotherapy for Breast Cancer : Characteristics, Course, and Correlates. 1999;18(4):233-42.

15. Logan HL, Tomar SL, Chang M, Turner GE, Mendenhall WM, Jr CER. Selecting a comparison group for 5-year oral and pharyngeal cancer survivors : Two methods. 2012;

16. Prue G, Allen J, Gracey J, Rankin J, Cramp F. Fatigue in Gynecological Cancer Patients During and After Anticancer Treatment. J Pain Symptom Manage [Internet]. 2010;39(2):197-210. Available from: http://dx.doi.org/10.1016/j.jpainsymman.2009.06.011

17. Marteau TM, Bekker H. The development of a six-item short-form of the state scale of the Spielberger State-Trait Anxiety Inventory (STAI). Br J Clin Psychol. 1992;31 ( Pt 3):301-6.

18. Korfage IJ, Essink-Bot M-L, Janssens A, Schroder FH, de Koning HJ. Anxiety and depression after prostate cancer diagnosis and treatment : 5-year follow-up. Br J Cancer. 2006;94:1093-8.

19. Venderbos LDF, Aluwini S, Roobol MJ, Bokhorst LP, Oomens E, Bangma C, et al. Five-year follow-up after active surveillance or curative treatment: preliminary quality of life outcomes of men with prostate cancer. Qual Life Res. 2017 Oct;26:1635-45. 
20. Bender R, Lange S. Adjusting for multiple testing: when and how? J Clin Epidemiol [Internet]. 2017;54(4):343-9. Available from: http://dx.doi.org/10.1016/S08954356(00)00314-0

21. Roth AJ, Rosenfeld B, Kornblith AB, Gibson C, Scher HI, Curley-Smart T, et al. The memorial anxiety scale for prostate cancer: Validation of a new scale to measure anxiety in men with prostate cancer. Cancer. 2003;97:2910-8.

22. Radloff L. The CES-D Scale : A Self-Report Depression Scale for Research in the General Population. Appl Psychol Meas. 1977;1(3):385-401.

23. van den Bergh RC, Essink-Bot ML, Roobol MJ, Wolters T, Schroder FH, Bangma $\mathrm{CH}$, et al. Anxiety and distress during active surveillance for early prostate cancer. Cancer [Internet]. 2009 Sep 1;115(17):3868-78. Available from: http://queens.ezp1.qub.ac.uk/login?url=http://ovidsp.ovid.com/ovidweb.cgi?T=JS\&CS $\mathrm{C}=\mathrm{Y} \& \mathrm{NEWS}=\mathrm{N} \& \mathrm{PAGE}=$ fulltext $\& \mathrm{D}=\mathrm{med} 5 \& \mathrm{AN}=19637245$

24. Venderbos LDF, van den Bergh C.N. R, Roobol MJ, H. FS, Essink-Bot M, Bangma $\mathrm{CH}$, et al. A longitudinal study on the impact of active surveillance for prostate cancer on anxiety and distress levels. Psychooncology [Internet]. 2015;24(3):348-54.

Available from:

http://search.ebscohost.com/login.aspx?direct=true \&db=jlh\&AN=109777661\&site=eh ost-live

25. Herdman M, Gudex C, Lloyd A, Janssen M, Kind P, Parkin D, et al. Development and preliminary testing of the new five-level version of EQ-5D (EQ-5D-5L). 2011;20:1727-36.

26. Van Den Bergh RCN, Essink-Bot ML, Roobol MJ, Wolters T, Schroder FH, Bangma $\mathrm{CH}$, et al. Anxiety and distress during active surveillance for early prostate cancer: A longitudinal analysis. J Urol 2009 Am Urol Assoc Annu Meet Chicago, United StatesConference Start 20090425 Conf End 20090430Conference Publ [Internet]. 2009;181(4 SUPPL. 1):179. Available from: http://queens.ezp1.qub.ac.uk/login?url=http://ovidsp.ovid.com/ovidweb.cgi?T=JS\&CS $\mathrm{C}=\mathrm{Y} \& \mathrm{NEWS}=\mathrm{N} \& \mathrm{PAGE}=$ fulltext $\& \mathrm{D}=$ emed9\&AN $=70112598$

27. Cancer IA for R on. GLOBOCAN 2012: estimated cancer incidence, mortality and prevalence worldwide in 2012. 2012. 
28. Ruane-McAteer E, Porter S, O’Sullivan JM, Prue G. A Cognitive-Emotional See-Saw: Men's experiences of undergoing active surveillance for prostate cancer. Psychooncology. 2018;27(S3):170.

29. Aning JJ, Wassersug RJ, Goldenberg SL. Patient preference and the impact of decision-making aids on prostate cancer treatment choices and post-intervention regret. $2012 ; 19: 37-44$.

30. Couper JW, Love AW, Dunai J V, Duchesne GM, Bloch S, Costello AJ, et al. The psychological aftermath of prostate cancer treatment choices: a comparison of depression, anxiety and quality of life outcomes over the 12 months following diagnosis. Med J Aust. 2009;190(7):S86-9.

31. S.M. P, C.H.E. W, D.E. V, B.T. H, K.R. N, C.B. B, et al. A Longitudinal Study of Predictors of Sexual Dysfunction in Men on Active Surveillance for Prostate Cancer. Sex Med [Internet]. 2015 Sep;3(3):156-64. Available from:

http://queens.ezp1.qub.ac.uk/login?url=http://ovidsp.ovid.com/ovidweb.cgi?T=JS\&CS $\mathrm{C}=\mathrm{Y} \& \mathrm{NEWS}=\mathrm{N} \& \mathrm{PAGE}=$ fulltext $\& \mathrm{D}=$ emed $17 \& A N=606160433$;

32. Selli C, Bjartell A, Burgos J, Somerville M, Palacios J-M, Benjamin L, et al. Burden of illness in prostate cancer patients with a low-to-moderate risk of progression: A one-year, pan-european observational study. Prostate Cancer [Internet]. 2014;2014. Available from:

http://queens.ezp1.qub.ac.uk/login?url=http://ovidsp.ovid.com/ovidweb.cgi?T=JS\&CS $\mathrm{C}=\mathrm{Y} \& \mathrm{NEWS}=\mathrm{N} \& \mathrm{PAGE}=$ fulltext\&D$=$ emed1 $1 \& A N=2014235729$

33. van den Bergh RCN, Korfage IJ, Borsboom GJJM, Steyerberg EW, EssinkBot M. Prostate cancer-specific anxiety in Dutch patients on active surveillance: Validation of the memorial anxiety scale for prostate cancer. Qual Life Res An Int J Qual Life Asp Treat Care Rehabil [Internet]. 18(8):1061-6. Available from: http://queens.ezp1.qub.ac.uk/login?url=http://ovidsp.ovid.com/ovidweb.cgi?T=JS\&CS $\mathrm{C}=\mathrm{Y} \& \mathrm{NEWS}=\mathrm{N} \& \mathrm{PAGE}=$ fulltext $\& \mathrm{D}=\mathrm{psyc} 6 \& \mathrm{AN}=2009-16750-012$

34. Parker PA, Davis JW, Latini DM, Baum G, Wang X, Ward JF, et al. The Relationship Between Illness Uncertainty, Anxiety, Fear of Progression, and Quality of Life in Men With Favorable Risk Prostate Cancer Undergoing Active Surveillance. BJU Int [Internet]. 2015 Feb 24 [cited 2015 Mar 12];n/a-n/a. Available from: 
http://www.ncbi.nlm.nih.gov/pubmed/25714186

35. Salzburg Global Seminar. The Salzburg Statement on Shared Decision Making. 2011;(February).

36. Whelan P. The Long Perspective: Prostate Cancer as a Chronic Disease [Internet]. Prostate Cancer. 2014. (Wiley Online Books). Available from: https://doi.org/10.1002/9781118347379.ch16

37. Donovan J, Hamdy F, Neal D, Peters T, Oliver S, Brindle LA, et al. Prostate Testing for Cancer and Treatment (ProtecT) Feasibility Study. Health Technol Assess (Rockv). $2003 ; 7(14)$

38. Entwistle VA, Carter SM, Cribb A, Mccaffery K. Supporting Patient Autonomy: The Importance of Clinician-patient Relationships. 2010;

39. van Stam M-A. Shared Decision-Making in Prostate Cancer Care [Internet]. University Medical Center Utrecht; 2018. Available from: https://dspace.library.uu.nl/handle/1874/364929

40. CSO CSO, NISRA NIS and RA. Census 2011 Ireland and Northern Ireland. 2014. 
Tables

Table 1. Participant Demographic Characteristics

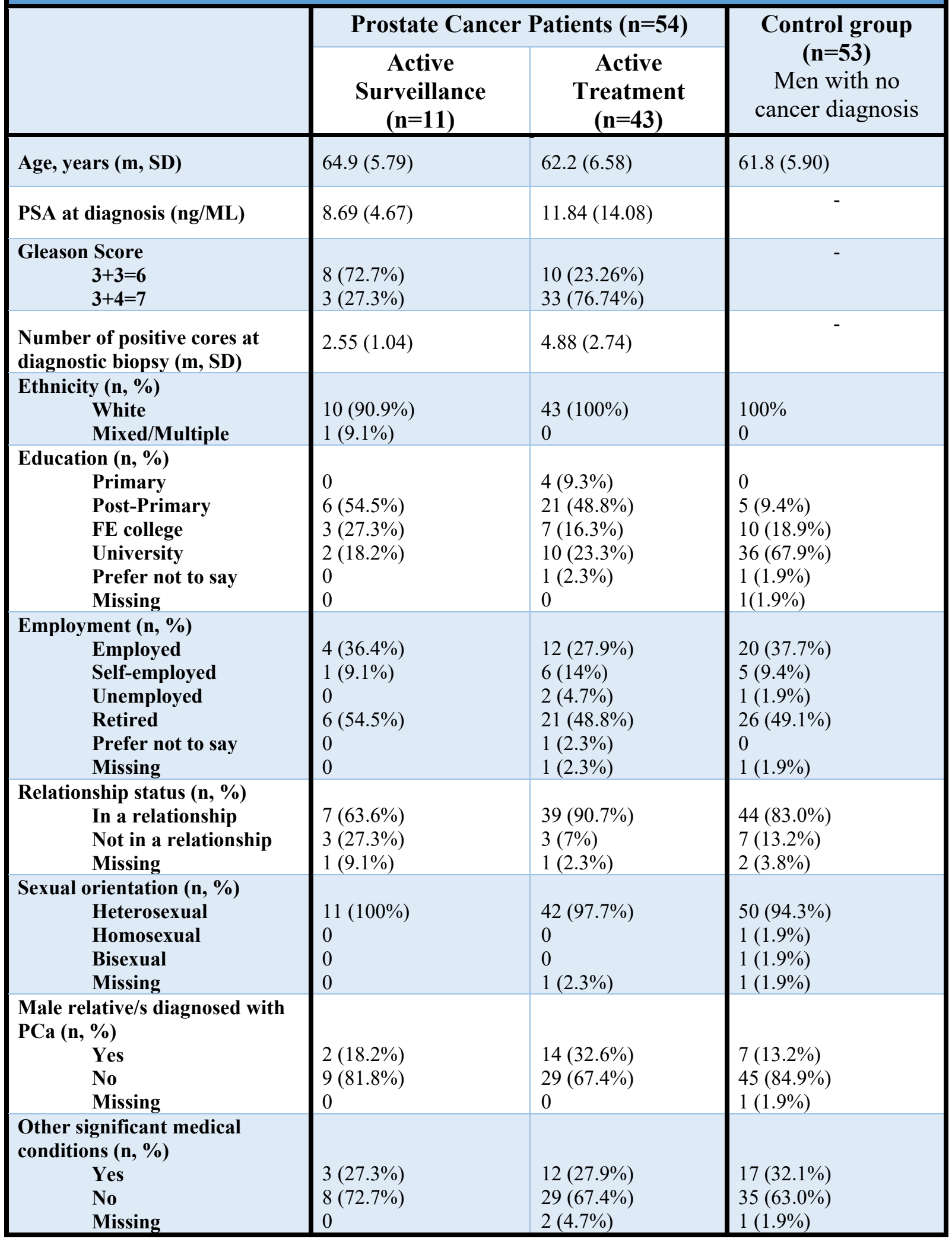




\begin{tabular}{|c|c|c|c|c|c|c|c|c|c|c|c|c|}
\hline & \multicolumn{8}{|c|}{ Prostate Cancer Patients $(n=54)$} & \multirow{2}{*}{\multicolumn{4}{|c|}{$\begin{array}{l}\text { Control group }(\mathbf{n}=\mathbf{5 3}) \\
\text { Men with no cancer diagnosis }\end{array}$}} \\
\hline & \multicolumn{4}{|c|}{ Active Surveillance $(n=11)$} & \multicolumn{4}{|c|}{ Active Treatment $(n=43)$} & & & & \\
\hline & $\begin{array}{l}\text { Time } 1 \\
(n=11)\end{array}$ & $\begin{array}{l}\text { Time } 2 \\
(n=10)\end{array}$ & $\begin{array}{l}\text { Time } 3 \\
(n=10)\end{array}$ & $\begin{array}{l}\text { Time } 4 \\
(n=9)\end{array}$ & $\begin{array}{l}\text { Time 1 } \\
(n=43)\end{array}$ & $\begin{array}{l}\text { Time } 2 \\
(n=37)\end{array}$ & $\begin{array}{l}\text { Time } 3 \\
(n=37)\end{array}$ & $\begin{array}{l}\text { Time } 4 \\
(n=34)\end{array}$ & $\begin{array}{l}\text { Time 1 } \\
(n=53)\end{array}$ & $\begin{array}{l}\text { Time } 2 \\
(n=46)\end{array}$ & $\begin{array}{l}\text { Time } 3 \\
(n=45)\end{array}$ & $\begin{array}{l}\text { Time } 4 \\
(n=40)\end{array}$ \\
\hline $\begin{array}{l}\text { Depression symptoms } \\
\text { (CES-D; m, SD) } \\
{[\text { Clin threshold } \geq 16]}\end{array}$ & $\begin{array}{l}10.333 \\
(9.33)\end{array}$ & $\begin{array}{c}11.11 \\
(12.33)\end{array}$ & $\begin{array}{l}13.44 \\
(13.44)\end{array}$ & $\begin{array}{c}11.33 \\
(14.33)\end{array}$ & $\begin{array}{l}10.78 \\
(8.45)\end{array}$ & $\begin{array}{l}11.30 \\
(9.40)\end{array}$ & $\begin{array}{l}10.55 \\
(8.60)\end{array}$ & $\begin{array}{c}8.88 \\
(8.45)\end{array}$ & $\begin{array}{c}6.83 \\
(7.71)\end{array}$ & $\begin{array}{c}7.03 \\
(9.00)\end{array}$ & $\begin{array}{l}7.18 \\
(9.15)\end{array}$ & $\begin{array}{c}6.70 \\
(10.00)\end{array}$ \\
\hline $\begin{array}{l}\text { Generalised anxiety } \\
\text { symptoms (STAI-6; m, } \\
\text { SD) } \\
{[\text { Clin threshold } \geq 44]}\end{array}$ & $\begin{array}{l}36.56 \\
(12.02)\end{array}$ & $\begin{array}{c}36.89 \\
(15.37)\end{array}$ & $\begin{array}{l}38.46 \\
(18.45)\end{array}$ & $\begin{array}{c}38.89 \\
(16.83)\end{array}$ & $\begin{array}{c}37.73 \\
(12.51)\end{array}$ & $\begin{array}{c}34.94 \\
(12.67)\end{array}$ & $\begin{array}{c}31.67 \\
(10.35)\end{array}$ & $\begin{array}{c}32.67 \\
(12.49)\end{array}$ & $\begin{array}{c}28.25 \\
(11.06)\end{array}$ & $\begin{array}{c}27.63 \\
(10.76)\end{array}$ & $\begin{array}{l}28.16 \\
(12.17)\end{array}$ & $\begin{array}{c}28.21 \\
(12.68)\end{array}$ \\
\hline $\begin{array}{l}\text { PCa-specific anxiety } \\
\text { symptoms (MAX-PC; } \\
\text { m, SD) } \\
{[\text { Clin threshold } \geq 27]}\end{array}$ & $\begin{array}{c}22.78 \\
(11.96)\end{array}$ & $\begin{array}{c}20.78 \\
(15.45)\end{array}$ & $\begin{array}{c}20.11 \\
(13.03)\end{array}$ & $\begin{array}{c}20.22 \\
(13.94)\end{array}$ & $\begin{array}{l}16.24 \\
(9.63)\end{array}$ & $\begin{array}{l}14.38 \\
(8.06)\end{array}$ & $\begin{array}{c}12.71 \\
(8.82)\end{array}$ & $\begin{array}{l}12.79 \\
(8.83)\end{array}$ & - & - & - & - \\
\hline
\end{tabular}




\section{Figure legends}

Figure 1. Study procedure flow chart

Figure 2. Flow diagram of potential participants and respondents at each time point. 